\title{
Klasifikasi Channel Youtube Indonesia Menggunakan Algoritma C4.5
}

\author{
Ardi Ramadhan Sukma ${ }^{1}$,Riqadri Halfis ${ }^{2}$,Ady Hermawan ${ }^{3}$ \\ ${ }^{1}$ Pasca Sarjana Ilmu Komputer, STMIK Nusa Mandiri, Indonesia \\ 1.ardirsukma40@gmail.com \\ ${ }^{2}$ Pasca Sarjana Ilmu Komputer, STMIK Nusa Mandiri, Indonesia \\ 2arizhboys@gmail.com \\ ${ }^{3}$ Pasca Sarjana Ilmu Komputer, STMIK Nusa Mandiri, Indonesia \\ 3ady.hermawan31@gmail.com
}

Cara Sitasi: Sukma, A. R., Halfis , R., \& Hermawan, A. (2019). Klasifikasi Chanel Youtube Indnesia Menggunakan Algoritma C 4.5. Jurnal Teknik Komputer, 21-28.

\begin{abstract}
In the current era, social media is very influential in our lives whether from Instagram, Twitter, Youtube, or others. One of them is social media Youtube which has a very important role for the public, even though public figures. Youtube provides very interesting content for those who have a channel because they have an assessment of Video Upload, Subscriber, Video Viewers. Even Youtube provides an opportunity for Youtube channels that install Google AdSense to be paid to the owner of the Channel. Youtube Channel ratings can be rated from Video Upload, Subscriber, Video Viewers. From the Youtube data processing data can be done. One data processing technique that can be used in the process is classification. Classification is a data processing technique that divides objects into classes according to the desired number of classes. And using the C4.5 algorithm in the classification process. Who can determine the Youtube Channel especially Indonesia with a Very Good or Good ratio.
\end{abstract}

Keywords : Algoritma C4.5, Indonesia, Youtube, Data Mining, Classification

\section{PENDAHULUAN}

\section{Latar Belakang}

Pada zaman saat ini perkembangan media sosial khususnya di Indonesia sangat pesat, berbagai informasi dapat di terima dengan media sosial. Media sosial merupakan sebuah media daring, dengan para penggunanya bisa dengan mudah berpartisipasi, berbagi, dan menciptakan isi meliputi blog, jejaring sosial, wiki, forum dan dunia virtual. Blog, jejaring sosial dan wiki merupakan bentuk media sosial yang paling umum digunakan oleh masyarakat di seluruh dunia. Banyak sekali jejaring sosial di dunia maya salah satu nya Youtube.

Youtube merupakan sebuah situs web berbagi video yang dibuat oleh tiga mantan karyawan PayPal pada Februari 2005. Situs ini memungkinkan pengguna mengunggah, menonton, dan berbagi video. Perusahaan ini berkantor pusat di San Bruno, California, dan memakai teknologi Adobe Flash Video dan HTML5 untuk menampilkan berbagai macam konten video buatan pengguna, termasuk klip film, klip TV, dan video musik. Selain itu ada pula konten amatir seperti blog video, video orisinal pendek, dan video pendidikan. $\mathrm{Di}$ Youtube bisa mendapatkan penghasilan dari Google AdSense atau pun Video Upload, Subscriber, Video Viewers. Dengan Metode C4.5 saya akan penelitian dengan atribut Catergory, Video Upload, Subscriber, Video Viewers, dan Ratio.

Algoritma C4.5 adalah algoritma yang digunakan untuk menghasilkan sebuah pohon keputusan yang dikembangkan oleh Ross qiunlan.Ide dasar dari algoritma ini adalah pembuatan pohon keputusan berdasarkan pemilihan atribut yang memiliki prioritas tertinggi atau dapat disebut memiliki nilai gain tertinggi berdasarkan nilai entropy atribut tersebut sebagai poros atribut klasifikasi. Pada tahapannya algoritma C4.5 memiliki 2 prinsip kerja, yaitu: Membuat pohon keputusan, dan membuat aturan-aturan (rule model). Aturan aturan yang terbentuk dari pohon keputusan akan membentuk suatu kondisi dalam bentuk if then. 
2. Rumusan Masalah

Bagaimana menerapkan Algortima untuk mengklasifikasikan Channel Youtube Indonesia?

\section{Tujuan Penelitian}

Untuk mengetahui klasifikasi channel youtube Indonesia dengan melihat ratio menggunakan Algoritma C4.5.

4. Metode Penelitian

a. Melakukan pengumpulan data Channel Youtube Indonesia.

b. Menggunakan Algoritma C4.5 untuk klasifikasi Channel Youtube Indonesia.

\section{Data Mining}

Data mining yang di kenal dengan nama pattern recognition adalah metode pengolahan untuk menemukan suatu pola yang tersembunyi untuk dapat di olah menjadi pengetahuan dan ilmu pengetahuan baru dan informasi dari data dan hasil untuk keputusan di masa depan.

Data mining juga dapat di sebut sebagai sistem pengolahan data yang sangat besar, yang memberikan peranan dalam beberapa bidang di dunia yaitu bidang keuangan, industri, transportasi, cuaca, dan teknologi. Dalam data mining juga terdapat metode metode yang dapat di gunakan antara lain metode klasifikasi, clustering, regresi, seleksi variabel, dan market bisnis. Data mining dapat di artikan sebagai data dalam jumlah besar yang di simpan dalam suatu database, data warehouse untuk menyimpan dapat sehingga dapat menemukan pola. Ada beberapa teknik dalam data mining antara lain data analisis, signal proccesing, neural network dan pengenalan pola.

\section{Fungsi Data Mining}

Data mining mempunyai fungsi yang penting untuk membantu mendapatkan informasi yang berguna serta meningkatkan pengetahuan bagi pengguna. Pada dasarnya, data mining mempunyai empat fungsi dasar yaitu:

a. Fungsi Prediksi (prediction). Proses untuk menemukan pola dari data dengan menggunakan beberapa variabel untuk memprediksikan variabel lain yang tidak diketahui jenis atau nilainya.

b. Fungsi Deskripsi (description). Proses untuk menemukan suatu karakteristik penting dari data dalam suatu basis data. c. Fungsi Klasifikasi (classification). Klasifikasi merupakan suatu proses untuk menemukan model atau fungsi untuk menggambarkan class atau konsep dari suatu data. Proses yang digunakan untuk mendeskripsikan data yang penting serta dapat meramalkan kecenderungan data pada masa depan.

d. Fungsi Asosiasi (association). Proses ini digunakan untuk menemukan suatu hubungan yang terdapat pada nilai atribut dari sekumpulan data.

\section{Tahapan Data Mining}

Tahapan yang dilakukan pada proses data mining diawali dari seleksi data dari data sumber ke data target, tahap preprocessing untuk memperbaiki kualitas data, transformasi, data mining serta tahap interpretasi dan evaluasi yang menghasilkan output berupa pengetahuan baru yang diharapkan memberikan kontribusi yang lebih baik. Secara detail dijelaskan sebagai berikut (Fayyad, 1996):

a. Data selection

Pemilihan (seleksi) data dari sekumpulan data operasional perlu dilakukan sebelum tahap penggalian informasi dalam KDD dimulai. Data hasil seleksi yang digunakan untuk proses data mining, disimpan dalam suatu berkas, terpisah dari basis data operasional.

\section{b. Pre-processing / cleaning}

Sebelum proses data mining dapat dilaksanakan, perlu dilakukan proses cleaning pada data yang menjadi fokus KDD. Proses cleaning mencakup antara lain membuang duplikasi data, memeriksa data yang inkonsisten, dan memperbaiki kesalahan pada data.

\section{c. Transformation}

Coding adalah proses transformasi pada data yang telah dipilih, sehingga data tersebut sesuai untuk proses data mining. Proses coding dalam KDD merupakan proses kreatif dan sangat tergantung pada jenis atau pola informasi yang akan dicari dalam basis data.

\section{d. Data mining}

Data mining adalah proses mencari pola atau informasi menarik dalam data terpilih dengan menggunakan teknik atau metode tertentu. Teknik, metode, atau algoritma dalam data mining sangat bervariasi. Pemilihan metode atau algoritma yang tepat sangat bergantung pada tujuan dan proses KDD secara keseluruhan.

e. Interpretation / evalution 
Pola informasi yang dihasilkan dari proses data mining perlu ditampilkan dalam bentuk yang mudah dimengerti oleh pihak yang berkepentingan. Tahap ini merupakan bagian dari proses KDD yang disebut interpretation. Tahap ini mencakup pemeriksaan apakah pola atau informasi yang ditemukan bertentangan dengan fakta atau hipotesis yang ada sebelumnya.

\section{Algoritma C4.5}

Algoritma C4.5 adalah algoritma yang digunakan untuk menghasilkan sebuah pohon keputusan yang dikembangkan oleh Ross qiunlan.Ide dasar dari algoritma ini adalah pembuatan pohon keputusan berdasarkan pemilihan atribut yang memiliki prioritas tertinggi atau dapat disebut memiliki nilai gain tertinggi berdasarkan nilai entropy atribut tersebut sebagai poros atribut klasifikasi. Pada tahapannya algoritma C4.5 memiliki 2 prinsip kerja, yaitu: Membuat pohon keputusan, dan membuat aturan-aturan (rule model). Aturan aturan yang terbentuk dari pohon keputusan akan membentuk suatu kondisi dalam bentuk if then.

Terdapat empat langkah dalam proses pembuatan pohon keputusan pada algoritma $\mathrm{C} 4.5$, yaitu:

a. Memilih atribut sebagai akar, didasarkan pada nilai gain tertinggi dari atribut-atribut yang ada.

b. Membuat cabang untuk masing-masing nilai, artinya membuat cabang sesuai dengan jumlah nilai variabel gain tertinggi.

c. Membagi setiap kasus dalam cabang, berdasarkan perhitungan nilai gain tertinggi dan perhitungan dilakukan setelah perhitungan nilai gain tertinggi awal dan kemudian dilakukan proses perhitungan gain tertinggi kembali tanpa meyertakan nilai variabel gain awal.

d. Mengulangi proses dalam setiap cabang sehingga semua kasus dalam cabang memiliki kelas yang sama, mengulangi semua proses perhitungan gain tertinggi untuk masing-masing cabang kasus sampai tidak bisa lagi dilakukan proses perhitungan.

Algoritma C4.5 secara rekursif mengunjungi setiap simpul keputusan, memilih pembagian yang optimal, sampai tidak bisa dibagi lagi. Dari ketiga peneliti yang telah dilakukan tersebut, klasifikasi dengan Algoritma C4.5 digunakan oleh para peneliti sebagai solusi untuk mengambil keputusan yang diharapkan mampu membantu dalam pengambilan keputusan dengan lebih mudah dan cepat.
Dalam penerapan dan penggunaan algoritma C4.5, dapat digunakan untuk melakukan prediksi dan klasifikasi terhadap calon pegawai yang berpotensi untuk masuk ke dalam perusahaan dengan cara membuat pohon keputusan berdasarkan data-data yang sudah ada dan melakukan prediksi terhadap calon pegawai baru yang ingin masuk ke perusahaan. Selain itu algoritma ini digunakan untuk klasifikasi predikat keberhasilan mahasiswa disebuah universitas. Variabel yang memiliki prioritas utama terhadap predikat keberhasilan mahasiswa adalah mahasiswa yang memilih sesi perkuliahan pada pagi hari.

\section{Pohon Keputusan (Decision Tree)}

Pohon keputusan adalah sebuah struktur yang dapat digunakan untuk mengubah data menjadi pohon keputusan yang akan menghasilkan aturan-aturan keputusan besar menjadi himpunan-himpunan record yang lebih kecil dengan menerapkan serangkaian aturan keputusan. Pohon keputusan yang dihasilkan oleh algoritma C4.5 dapat digunakan untuk klasifikasi. Pohon keputusan adalah salah satu teknik penambangan data yang paling populer untuk penemuan pengetahuan. Secara sistematis menganalisis dan mengekstrak aturan untuk tujuan Klasifikasi / prediksi.

\section{Entropy dan Information Gain}

Entropy adalah ukuran dari teori informasi yang dapat mengetahui karakteristik dari impuryt dan homogenity dari kumpulan data. Dari nilai Entropy tersebut kemudian dihitung nilai information gain masing-masing atribut. Penghitungan nilai Entropy digunakan rumus seperti dalam Persamaan (1).

Entropy ()$=\sum=0-* \log _{2}()$

Rumus (1) merupakan rumus yang digunakan dalam perhitungan entropy yang digunakan untuk menentukan seberapa informatif atribut tersebut. Berikut keterangannya :

s : Himpunan kasus

$\mathrm{n} \quad$ : Jumlah partisi atribut A

$|\mathrm{S} i| \quad$ : Jumlah kasus pada partisi ke- $i$

|S $\quad$ : Jumlah kasus dalam s

Information Gain adalah informasi yang didapatkan dari perubahan entropy pada suatu kumpulan data, baik melalui observasi atau bisa juga disimpulkan dengan cara melakukan partisipasi terhadap suatu set data.

$\operatorname{GAIN}(, \mathrm{A})=\operatorname{Entropy}()-\sum=1-\left|{ }_{\mid} \mathrm{Si}_{\mathrm{S}}\right|(\mathrm{C}) \ldots(2)$

Rumus (2) merupakan rumus yang digunakan dalam perhitungan information gain setelah melakukan perhitungan entropy. Berikut keterangannya :

s : Himpunan kasus

n : Jumlah partisi atribut A 
$|\mathrm{S} i| \quad$ : Jumlah kasus pada partisi ke- $i$

$|\mathrm{S}| \quad$ : Jumlah kasus dalam $\mathrm{s}$

Dengan mengetahui rumus-rumus diatas, data yang telah diperoleh dapat dimasukkan dan diproses dengan algoritma C4.5 untuk proses pembuatan decision tree.

\section{Refrensi Penelitian}

a. Predicting Students' Performance Using ID3 And C4.5 Classfication Algorithms

Penerbit : Kalpesh Adhartao, Aditya Gaykar, Amiraj Dhawan, Rohit Jha and Vipul Honrao

Algoritma : ID3 dan C4.5

Objek Penelitian : Students Performance

Output : Memprediksi Performance Student

b. Data Mining : A Prediction for Academic Performance Improvement of Science Students using Classification

Penerbit : I.A Ganiyu

Algoritma : C4.5

Objek Penelitian : Academic Performance

Output : Prediksi Performance Pelajar Science menggunakan Kalsifikasi

c. Classification Thourgh Machine Learning Technique : C4.5 Algorithms based on Various Entropies

Penerbit : Seema, Jitendra Agrawal, Sanjeev Sharma

Algoritma : C4.5

Objek Penelitian : Various Entropies

Output : Klasifikasi Berbagia Entropi

d. Penerapan Algorimtma C4.5 untuk Penetuan Tingkat Konsumsi Konsumen pada Medan Solusindo

Penerbit : Mardi Turnip, Charles Wijaya

Algoritma : C4.5

Objek Penelitian : Tingkat Konsumsi Konsumen

Output : Menyediakan informasi yang

diperlukan pihak manajemen, klasifikasi tingkat konsumsi konsumen

e. Penerapan Decision Tree Untuk Penentuan Pola Data Penerimaan Mahasiswa Baru

Penerbit : Aradea, Satriyo A., Ariyan Z., Yaliana A.

Algoritma : C4.5

Objek Penelitian : Penentuan Penerimaan Beasiswa

Output : Klasifikasi Penentuan Pola PMB

\section{Objek Penelitian}

Objek Penelitian adalah Channle Youtube Indonesia berdasarkan Video Upload, Subscribers, Video Viewers, dan Ratio dimana Ratio sebagai label untuk mengklasifikasi.

\section{METODOLOGI PENELITIAN}

Metode Penelitian yang digunakan dalam penerapan algoritma C4.5 untuk klasifikasi Channel Youtube Indesia, menggunakan rancangan penelitian sebagai berikut :

1. Pengumpulan Data

Pengumpulan data adalah mengumpulkan datadata yang akan digunakan dalam proses algoritma klasifikasi C4.5.

2. Tranformasi dan Seleksi Data

Transformasi data adalah proses mentransformasi atau mengubah data ke dalam bentuk yang sesuai, agar dapat di proses dengan perhitungan algoritma C4.5. Transformasi Data adalah proses mentransformasi atau menggabungkan data ke dalam bentuk yang sesuai untuk penggalian lewat operasi summary atau aggregation.

3. Perhitungan Entropy dan Information Gain

Perhitungan semua atribut/variabel, entropy menggunakan rumus (1) dan information gain menggunakan rumus (2) untuk mengetahui information gain tertinggi yang akan dijadikan simpul akar pada pembuatan pohon keputusan.

4. Pohon Keputusan (Decision Tree)

Pohon keputusan adalah hasil dari proses perhitungan entropy dan information gain, setelah perhitungan berulang-ulang sampai semua atribut pohon memiliki kelas dan tidak bisa lagi dilakukan proses perhitungan.

5. Rule Model

Aturan-aturan/ Rule model adalah uraian penjelasan yang merepresentasikan sebuah pohon keputusan.

6. Validasi dan Pengujian

Validasi dan pengujian adalah Pengujian yang dilakukan untuk mengetahui semua fungsi bekerja dengan baik atau tidak. Validasi dilakukan dengan Ten-fold Cross Validation. Ten-fold Cross Validation adalah validasi yang dilakukan dengan cara membagi suatu set data menjadi sepuluh segmen yang berukuran sama besar dengan cara melakukan pengacakan data. Validasi dan pengujian dilakukan untuk mengetahui tingkat akurasi, presisi, dan recall dari hasil prediksi klasifikasi. Akurasi adalah persentase dari catatan yang diklasifikasikan dengan benar dalam pengujian dataset. Presisi 


\begin{tabular}{|c|c|c|c|c|c|}
\hline $\begin{array}{l}\text { Channel } \\
\text { name }\end{array}$ & Category & $\begin{array}{l}\text { Video } \\
\text { Upload }\end{array}$ & $\begin{array}{l}\text { Subscrib } \\
\text { er }\end{array}$ & $\begin{array}{l}\text { Video } \\
\text { View }\end{array}$ & Ratio \\
\hline Indosiar & TV & $\begin{array}{l}\text { Menenga } \\
\mathrm{h}\end{array}$ & Tinggi & Tinggi & $\begin{array}{l}\text { Sang } \\
\text { at } \\
\text { Baik }\end{array}$ \\
\hline $\begin{array}{l}\text { RCTI - } \\
\text { Layar } \\
\text { Drama } \\
\text { Indonesia }\end{array}$ & TV & Tinggi & Tinggi & Tinggi & $\begin{array}{l}\text { Sang } \\
\text { at } \\
\text { Baik }\end{array}$ \\
\hline $\begin{array}{l}\text { TRANST } \\
\text { V Official }\end{array}$ & TV & Tinggi & Tinggi & Tinggi & $\begin{array}{l}\text { Sang } \\
\text { at } \\
\text { Baik }\end{array}$ \\
\hline$\cdots$ & $\cdots$ & $\cdots$ & $\cdots$ & $\cdots$ & $\ldots$ \\
\hline $\begin{array}{l}\text { Sony } \\
\text { Entertaime } \\
\text { nt } \\
\text { Indonesia }\end{array}$ & $\begin{array}{l}\text { Entertainme } \\
\mathrm{nt}\end{array}$ & Rendah & Rendah & $\begin{array}{l}\text { Menenga } \\
\mathrm{h}\end{array}$ & Baik \\
\hline $\begin{array}{l}\text { adala } \\
\text { seba } \\
\text { Reca } \\
\text { posit }\end{array}$ & $\begin{array}{l}\text { persenta } \\
\text { ii model b } \\
\text { adalah } \\
\text { sebenarny }\end{array}$ & $\begin{array}{l}\text { e data } \\
\text { lik yang } \\
\text { engukura } \\
\text {. }\end{array}$ & $\begin{array}{l}\text { yang di } \\
\text { sebenarr } \\
\text { an tingk: }\end{array}$ & $\begin{array}{l}\text { ylasifik } \\
\text { ya juga } \\
\text { peng }\end{array}$ & $\begin{array}{l}\text { sikan } \\
\text { baik. } \\
\text { nalan }\end{array}$ \\
\hline
\end{tabular}

\section{HASIL DAN PEMBAHASAN}

1. Pengumpulan Data

Pengumpulan Data dilakukan dengan cara mengambil di website socialblade.com/youtube/top/country/id. Data ini mencakup beberapa variable, antara lain : Rank, Grade, Channel name, Video Upload, Subscriber, Video view, yang akan diseleksi dengan algoritma C4.5. Jumlah data digunakan sebanyak 110 data Channel Youtube Indonesia.

Tabel 1.Data Channel Youtube Indonesia yang akan dijadikan data, dalam proses algoritma klasifikasi C4.5

\begin{tabular}{|c|c|c|c|c|c|}
\hline $\begin{array}{l}\text { Ran } \\
k\end{array}$ & $\begin{array}{l}\text { Grad } \\
\mathrm{e}\end{array}$ & $\begin{array}{l}\text { Channel } \\
\text { name }\end{array}$ & $\begin{array}{l}\text { Video } \\
\text { Uploa } \\
\text { d }\end{array}$ & $\begin{array}{l}\text { Subscrib } \\
\text { er }\end{array}$ & $\begin{array}{l}\text { Video } \\
\text { view }\end{array}$ \\
\hline $1^{\mathrm{st}}$ & $\mathrm{A}$ & Indosiar & 18994 & 4111015 & $\begin{array}{l}25335630 \\
33\end{array}$ \\
\hline $2^{\text {nd }}$ & $\mathrm{A}$ & $\begin{array}{l}\text { RCTI - Layar } \\
\text { Drama } \\
\text { Indonesia }\end{array}$ & 29466 & 3334422 & $\begin{array}{l}28790412 \\
90\end{array}$ \\
\hline $3^{\text {rd }}$ & $\mathrm{A}$ & $\begin{array}{l}\text { TRANSTV } \\
\text { Official }\end{array}$ & 27115 & 3351332 & $\begin{array}{l}19095569 \\
96\end{array}$ \\
\hline$\ldots$ & $\cdots$ & $\ldots$ & $\ldots$ & $\cdots$ & $\ldots$ \\
\hline $\begin{array}{l}110^{\mathrm{t}} \\
\mathrm{h}\end{array}$ & $\mathrm{B}+$ & $\begin{array}{l}\text { Sony } \\
\text { Entertaime } \\
\text { nt } \\
\text { Indonesia }\end{array}$ & 836 & 610916 & $\begin{array}{l}67990898 \\
1\end{array}$ \\
\hline
\end{tabular}

Sumber : socialblade.com(2018)

\section{Transformasi Data}

Transformasi data dilakukan dengan mengubah beberapa nilai atribut yang awalnya bernilai nominal menjadi nilai-nilai atribut yang sesuai dengan data pada Tabel 2 agar dapat dilakukan proses perhitungan algoritma klasifikasi C4.5.

\section{Tabel 2. Tabel Transformasi data}

\section{Perhitungan Entropy dan Information Gain}

Dengan cara menggunakan rumus Entropy kita dapat melakukan perhitungan jumlah keputusan "Sangat Baik" dan "Baik" dari seluruh kasus yang ada.

Entropy $($ Total $)=((-24 / 110) * \log 2(24 / 110)+(-$ $86 / 110) * \log 2(86 / 110))=0.7569834$

Jika sudah mendapatkan nilai Entropy dari tiap-tiap variable yang ada seperti Category, Video Upload, Subscriber, Video Viewers, Maka langkah selanjutnya menghitung Information Gain pada setiap atributnya.

Gain $($ Total, Category $)=(0.7569834)-$ $((4 / 110) * 0)-((30 / 110) * 0.650022)-$ $((23 / 110) * 0.558629)-((32 / 110) * 0.696212)$ $((16 / 100) * 0.954434)=0.121389$

Gain $($ Total, Video Upload $)=(0.7569834)-$ $((9 / 110) * 0.503258)-((4 / 110) * 0.8111278)-$ $((97 / 110) * 0.568363)=0.184965$

Gain ( Total, Subscriber $)=(0.7569834)-(($ $14 / 110) * 0.591673)-((42 / 110) * 0.775135)-$ $((54 / 110) * 0.309543)=0.233611$

Gain ( Total, Video Viewers $)=(0.7569834)-$ $((17 / 110) * 0.522559)-((77 / 110) * 0.520335)-$ $((16 / 110) * 0)=0.311184$

Setelah semuan Entropy dan Information Gain di hitung maka hasil perhitungan di masukan dalam tabel 3. Dari perhitungan di atas di ketahui bahwa Information gain terbesar adalah Video Viewers, maka dapat di jadikan simpul akar. Lalu ambil Information Gain terbesar yaitu Video Viewers lakukan perhitungan ulang dengan cara menghilangkan atribut yang terbesar tadi hingga semua atribut pohon memiliki kelas. 
Tabel 3. Hasil Perhitungan Entropy dan Information Gain

\begin{tabular}{|c|c|c|c|c|c|c|}
\hline & & jumlah & Sangat Baik & Baik & Entropy & Gain \\
\hline total & & 110 & 24 & 86 & 0.756834 & \\
\hline \multirow[t]{6}{*}{ Category } & & & & & & 0.121389 \\
\hline & E-commerce & 4 & 0 & 4 & 0 & \\
\hline & Entertainment & 30 & 5 & 25 & 0.650022 & \\
\hline & Musik & 23 & 3 & 20 & 0.558629 & \\
\hline & Personal & 32 & 6 & 26 & 0.696212 & \\
\hline & TV & 16 & 10 & 6 & 0.954434 & \\
\hline \multirow[t]{4}{*}{ Video Uploads } & & & & & & 0.184965 \\
\hline & Tinggi & 9 & 8 & 1 & 0.503258 & \\
\hline & Menengah & 4 & 3 & 1 & 0.811278 & \\
\hline & Rendah & 97 & 13 & 84 & 0.568363 & \\
\hline \multirow[t]{4}{*}{ Subscriber } & & & & & & 0.233611 \\
\hline & Tinggi & 14 & 12 & 2 & 0.591673 & \\
\hline & Menengah & 42 & 9 & 32 & 0.775135 & \\
\hline & Rendah & 54 & 3 & 51 & 0.309543 & \\
\hline \multirow[t]{4}{*}{ Video Views } & & & & & & 0.31184 \\
\hline & Tinggi & 17 & 15 & 2 & 0.522559 & \\
\hline & Menengah & 77 & 9 & 68 & 0.520335 & \\
\hline & Rendah & 16 & 0 & 16 & 0 & \\
\hline
\end{tabular}

Sumber : Hasil Penelitian(2019)

4. Pohon Keputusan (Decision Tree)

Dari hasil Perhitungan entropy dan information gain yang didapat kemudian diolah kedalam Decision Tree. Berikut hasil Pohon Keputusan (Decision Tree) : 


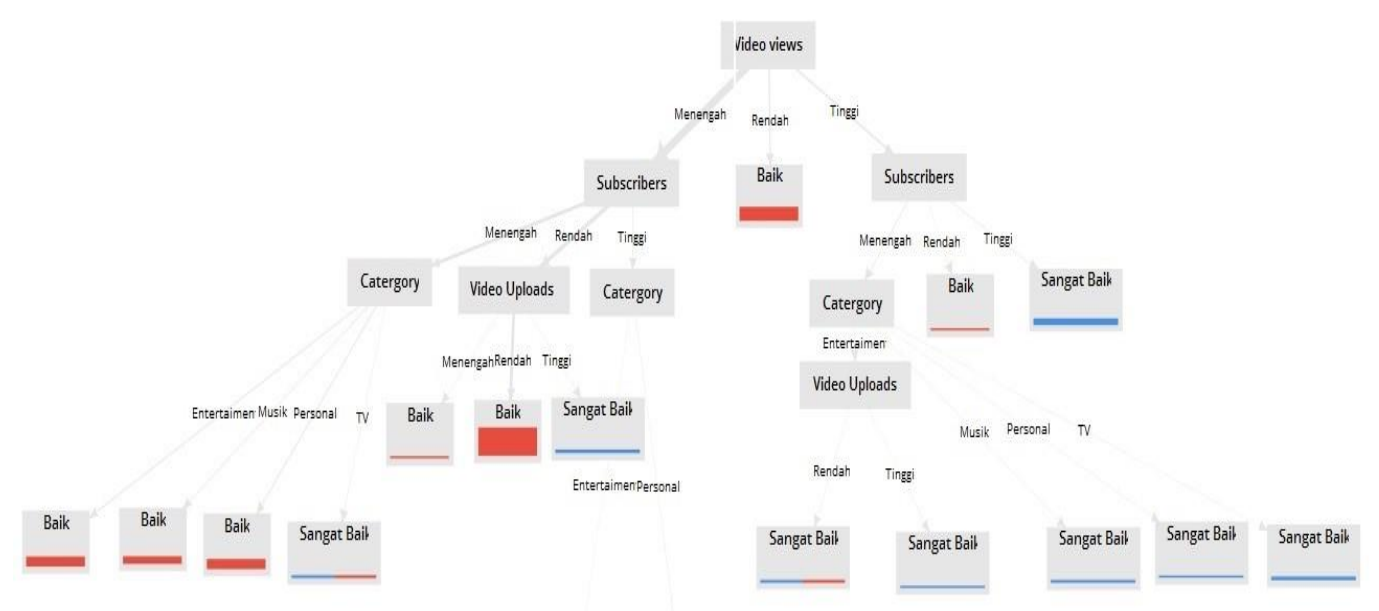

Sumber : Hasil Penelitian (2019)

Gambar 1. Pohon Keputusan (Decision Tree)

5. Rule Model

Dari pohon keputusan(decision tree) yang terbentuk pada Gambar 1 diatas, didapat aturanaturan/rule. Ada beberapa aturan yang terbentuk, dapat dilihat sebagai berikut ;

1. If Video Viewers $=$ Rendah then Ratio $=$ Baik

2. If Video Viewers=Menengah, and Subscriber=Menengah, Category=Entertaiment then Ratio $=$ Baik

3. If Video Viewers=Menengah, and Subscriber=Menengah, Category=Musik then Ratio $=$ Baik

4. If Video Viewers=Menengah, and Subscriber=Menengah, Category=Personal then Ratio $=$ Baik

5. If Video Viewers=Menengah, and Subscriber=Menengah, Category $=\mathrm{TV}$ then Ratio $=$ Sangat Baik

6. If Video Viewers=Menengah, and Subscriber=Rendah, Vidoe Uploads $=$ Menengah then Ratio=Baik

7. If Video Viewers=Menengah, and Subscriber=Rendah, Vidoe Uploads=Rendah then Ratio=Baik

8. If Video Viewers=Menengah, and Subscriber=Rendah, Vidoe Uploads=Tinggi then Ratio $=$ Sangat Baik
9. If Video Viewers=Menengah, and Subscriber=Tinggi, Category=Entertaiment then Ratio=Sangat Baik

10.If Video Viewers=Menengah, and Subscriber=Tinggi, Category=Personal then Ratio=Sangat Baik

11. If Video Viewers=Tinggi, and Subscriber=Tinggi then Ratio $=$ Sangat Baik

12. If Video Viewers=Tinggi, and Subscriber $=$ Rendah then Ratio=Baik

13. If Video Viewers=Tinggi, and Subscriber=Menengah, Category=Entertaiment, Video Uploads=Rendah then Ratio=Sangat Baik

14. If Video Viewers=Tinggi, and Subscriber=Menengah, Category=Entertaiment, Video Uploads=Tinggi then Ratio=Sangat Baik

15. If Video Viewers=Tinggi, and Subscriber=Menengah, Category=Musik then Ratio=Sangat Baik

16. If Video Viewers=Tinggi, and Subscriber=Menngah, Category=Personal then Ratio=Sangat Baik

17. If Video Viewers=Tinggi, and Subscriber=Menengah, Category $=\mathrm{TV}$ then Ratio=Sangat Baik 
6. Validasi dan Pengujian

Pengujian dilakukan dengan validasi silang. Salah satu jenis validasi silang adalah cross validation. Berikut hasil dari cross validation :

\begin{tabular}{|c|c|c|c|}
\hline & thue Sangat Baik & true Eaik & dass precisison \\
\hline pred. Sangat Eaik & 21 & 5 & $80.77 \%$ \\
\hline pred. Baik & 3 & 81 & $96.43 \%$ \\
\hline class recall & $87.50 \%$ & $94.19 \%$ & \\
\hline
\end{tabular}

Sumber : Hasil Penelitian (2019) Gambar 2. Hasil Cross Validation

Berdasarkan hasil pengujian dengan menggunakan Cross-Validation maka di dapatkan nilai akurasi $92.73 \%$ dengan class precesion Sangat Baik $80.77 \%$ dan class precision Baik $96.43 \%$, serta class recall Sangat Baik $87.50 \%$ dan class recall Baik 94.19\%.

\section{KESIMPULAN}

Kesimpulan dari penelitian ini adalah :

1.Penerapan Algoritma C4.5 akan dapan diimplementasikan pada ratio Channel Youtube Indonesia, dilihat dari akurasi yang mencapai $92.73 \%$, bahwa perhitungan yang dilakukan dapat memprediksi dan meklasifikasi ratio pada Youtube Channel Indonesia.

2. Terbentuk beberapa aturan atau rule model yang dapat digunakan sebagai acuan dalama membuat aplikasi GUI.

\section{REFERENSI}

Kalpesh Adhartao, Aditya Gaykar, Amiraj Dhawan, Rohit Jha and Vipul Honrao (2013). Predicting Students' Performance Using ID3 And C4.5 Classfication Algorithms, International Journal of Data Mining \& Knowledge Management Process. Departement of Computer Engineeing(India),Vol.3, No.5, pp. 39-52.

I.A Ganiyu (2016). Data Mining : A Prediction for Academic Performance Improvement of
Science Students using Classification, International Journal of Information and Communication Technelogy Research, Vol. 6, No. 4, ISSN 2223-4985. (Vol. 54).

Seema, Jitendra Agrawal, Sanjeev Sharma (2013). Classification Through Machine Learning Technique: C4.5 Algorithm based on Various Entropies, International Journal of Computer Application, Vol. 82, No. 16, pp 20-27.

Mardi Turnip, Charles Wijaya (2016). Penerapan Algoritma C4.5 untuk Penetuan Tingkat Konsumsi Konsumen pada Medan Solusindo, Jurnal Senopati (Seminar Nasional Pascasarjana Teknik Informatika), Vol. 1, No. 1, pp. 34-42,p-ISSN 2528-2832, e-ISSN 2549-7820.

Aradea, Satriyo A., Ariyan Z., Yaliana A. (2011). Penerapan Decision Tree Untuk Penentuan Pola Data Penerimaan Mahasiswa Baru, Jurnal Penelitian Sitrotika, Vol. 7, No. 1, 2011, ISSN 1693-9670.

SOCIALBLADE, Track User Statistic, website https://socialblade.com/.

\section{PROFIL PENULIS}

Ardi Ramadhan Sukma, S.Kom, lulus dari Program Sarjana(S1) Teknik Informatika di Univeristas Pembangunan Nasional "Veteran" Jakarta. Sekarang sedang melanjutakan Program Pasca Sarjana(S2) Magister Ilmu Komputer di STMIK Nusa Mandiri.

Riqadri Halfis, S.Kom, lulus dari Program Sarjana(S1) Sistem Informasi di STMIK Jayabaya. Sekarang sedang melanjutakan Program Pasca Sarjana(S2) Magister Ilmu Komputer di STMIK Nusa Mandiri.

Ady Hermawan, S.Kom, lulus dari Program Sarjana(S1) Teknik Informatika di STMIK Nusa Mandiri Jakarta. Sekarang sedang melanjutakan Program Pasca Sarjana(S2) Magister Ilmu Komputer di STMIK Nusa Mandiri. 